\title{
Surgical Aspects of the Possover LION Procedure: An Emerging Procedure for Recovery of Visceral Functions and Locomotion in Paraplegics
}

\author{
Uffe S Løve ${ }^{1} \odot$, Soren B Elmgreen ${ }^{2}$, Axel Forman ${ }^{3}$, Ivan Arsic ${ }^{4}$, Marc Possover ${ }^{5}$, Anette B Jønsson ${ }^{6}$, Helge Kasch ${ }^{7}$
}

\begin{abstract}
Background: Traumatic spinal cord injury (SCI) may be a devastating life event. Motor and sensory recovery after 6 months post-injury is sparse, despite intensive neurorehabilitation. Long-term disabling consequences may further reduce self-supportiveness and the quality of life. A new surgical intervention, the Possover LION procedure (Laparoscopic Implantation of Neuroprosthesis), may improve long-term perspectives providing the patient with an implantable pulse generator (IPG), and leads to pelvic situated nerves (sciatic and femoral nerves) to regain substantial motor and sensory functions in lower extremities.

Objective: To report from the surgical point of view, the experience of implementing an IPG system for direct nerve stimulation of pelvic nerves in a series of chronic traumatic SCl patients.

Methods: From two substudies, a feasibility study and a controlled clinical study, data from $21 \mathrm{SCl}$ patients with severe paraplegia who had undergone the Possover LION procedure were obtained. The Possover LION procedure was implemented in a surgical department with skilled surgeons in close collaboration with neurological expertise. The developer of the procedure performed the first operations and afterward provided guidance and collaboration.

Results: Twenty patients $(F=3, M=17$, age $=36.9 \pm 9.0$, ISCNSCI AIS A $=19$, AIS B $=1)$ with lesion between Th3 and L1 had IPG and four leads implanted. One patient had a "frozen pelvis" and could not be operated. During operation, severe bleeding was seen in one patient that could be stopped using on-site applied hemostats, with no need of transfusion. One patient had initial normalization of infection parameters postoperatively, but developed Staphylococcus aureus infection near the IPG, removal of IPG and leads was needed. Clinically significant dislocation of leads was seen in two patients and dislocation/tilting of IPG in one patient. Hardware problems with possible lead breakage were observed in one patient.

Conclusion: Posttraumatic SCI patients with paraplegia can be elected for the LION procedure by a specialist team of neurorehabilitation experts (neurologists, PTs), and skilled surgeons in the neuro-pelvic area, with Possover LION expertise. Complication rates for the Possover LION procedure are comparable to or better than those seen with spinal cord stimulation, and the procedure is generally safe. We recommend the monitoring of implanted leads and IPG using CT abdomen.

Keywords: Laparoscopy, Neurostimulation, Possover LION procedure, Traumatic spinal cord injury.

World Journal of Laparoscopic Surgery (2021): 10.5005/jp-journals-10033-1450
\end{abstract}

\section{INTRODUCTION}

Spinal cord injury (SCl) is frequent. The World Health Organization estimates an annual incidence of 250,000 to 500,000 cases. Individuals living with the consequences of $\mathrm{SCl}$ face numerous medical complications and reduced life expectancy as a direct or indirect result of their disability. 'Detrusor overactivity and sphincter dyssynergy are encountered in $85 \%$ of cases, and improved control of micturition and defecation closely follows the restoration of ambulation as primary rehabilitation goals of patients with $\mathrm{SCl}^{2}$ Inpatient rehabilitation entails training and to some extent restoration of body functions via conventional physiotherapy and occupational therapy augmented by electrical stimulation, be it either neuromuscular or functional. Nevertheless, recovery after the initial inpatient rehabilitation is at best modest, and the conversion rate of the American Spinal Injury Association Impairment Scale grade remains poor for grades A and B., Likewise, the rate of motor improvement declines over time, leaving many patients with permanent motor, sensory, and autonomic deficits. After 12 months from the sustained injury, a majority of $\mathrm{SCl}$ persons have essentially exhausted their possibility of further recovery. ${ }^{4,5}$
${ }^{1}$ Department of Surgery, Hospitalsenhed Midt, Viborg, Denmark

${ }^{2}$ Department of Clinical Medicine, Aarhus University, Aarhus, Denmark ${ }^{3}$ Department of Obstetrics and Gynecology, Aarhus University Hospital, Aarhus, Denmark

${ }^{4}$ Department of Radiology, Hospitalsenhed Midt, Viborg, Denmark

${ }^{5}$ Possover International Medical Center, Zürich, Switzerland

${ }^{6}$ Department of Neurology, Spinal Cord Injury Center of Western Denmark, Viborg, Denmark

${ }^{7}$ Department of Neurology, Hospitalsenhed Midt, Viborg, Denmark

Corresponding Author: Uffe S Løve, Department of Surgery, Hospitalsenhed Midt, Viborg, Denmark, Phone: +78446496 , e-mail: skovloeven@gmail.com

How to cite this article: Løve US, Elmgreen SB, Forman A, et al. Surgical Aspects of the Possover LION Procedure: An Emerging Procedure for Recovery of Visceral Functions and Locomotion in Paraplegics. World J Lap Surg 2021;14(2):75-80.

Source of support: Nil

Conflict of interest: None

(c) Jaypee Brothers Medical Publishers. 2021 Open Access This article is distributed under the terms of the Creative Commons Attribution 4.0 International License (https://creativecommons.org/licenses/by-nc/4.0/), which permits unrestricted use, distribution, and non-commercial reproduction in any medium, provided you give appropriate credit to the original author(s) and the source, provide a link to the Creative Commons license, and indicate if changes were made. The Creative Commons Public Domain Dedication waiver (http://creativecommons.org/publicdomain/zero/1.0/) applies to the data made available in this article, unless otherwise stated. 
A minimally invasive and fully reversible laparoscopic technique, the laparoscopic implantation of neuroprosthesis (the LION procedure), was developed by Possover for the precise placement of an implantable pulse generator (IPG) and placement of one to four leads for stimulating nerves of the lumbosacral plexus. A substantial number of published cases support the effect of the technique regarding the treatment of overactive and atonic bladder disturbances, neurogenic bowel dysfunction, and abdominopelvic neuropathic pain. ${ }^{6-10}$ Unexpectedly, the clinical observation was made that four patients with either complete or incomplete chronic traumatic $\mathrm{SCl}$ significantly regained motor and sensory function afterward having the LION procedure performed for bladder and bowel dysfunction. ${ }^{9}$ An updated case series of $18 \mathrm{SCl}$ patients having the LION procedure performed report that 16 are now capable of weight bearing standing and 12 are furthermore capable of voluntary stepping. ${ }^{11}$ Recently, the LION procedure has been carried out in collaboration between The Spinal Cord Injury Center of Western Denmark, Aarhus University Hospital, and Department of Surgery at Viborg Regional Hospital with the guidance and support from Professor Possover.

The Possover LION procedure has never before been described through a controlled, randomized trial, and potential side effects and safety aspects have not been prospectively evaluated.

The present study reports the surgical aspects and safety results and observed complications from (a) a feasibility study and (b) a randomized controlled study evaluating the effect of the Possover LION procedure.

\section{Materials and Methods}

The present study reports are obtained from a series of 21 eligible $\mathrm{SCl}$ patients having surgery at Viborg Regional Hospital, Denmark, with the Possover LION procedure. The presented study material is derived from two substudies: first, a feasibility study (substudy 1) with four eligible $\mathrm{SCl}$ patients and second, a randomized controlled study with two treatment arms (substudy 2) with the active group allocated to direct surgical intervention with performed Possover LION procedure and subsequent neurorehabilitation, and the control group allocated to delayed surgical intervention with 12 month of preconditioning using guided self-training with external neuromuscular electrical stimulation. Inclusion criteria: Traumatic SCI below level Th5 with spastic paraplegia, AIS grades A, B or C. Age between 18 and 50 years. Exclusion criteria: other implanted devices (e.g., cardiac pacemakers, baclofen pumps), severe episodes of dysautonomia, drug or alcohol abuse, unstable medical or psychiatric disorder, previous pelvic disorder or surgery that may interfere with the Possover LION procedure, planned pregnancy, known compliance issues, logistic obstacles (e.g., planned journeys, other planned surgery).

\section{Patients}

Twenty patients undergoing the Possover LION procedure at Viborg Regional Hospital were included in this study. One additional patient underwent operation, but the operation was aborted, and the patient failed to have the electrodes implanted due to a frozen pelvis.

\section{Ethics}

The study was conducted in accordance with the Helsinki II declaration. Patients gave verbal and written informed consent.
Substudy 1 did not need further approval. Substudy 2 was approved by the regional ethical committee (1-16-02-129-16) and the Danish Medical Agency (Journal no. 2017080415).

\section{Hardware}

Substudy 1 . In the feasibility part of the study, the St. Jude system with an EON mini IPG and four quattrode leads were implanted and the IPG programming was done using the St. Jude/Abbott Rapid Programmer System.

Substudy 2. In the controlled study, we used the Boston Scientific Precision Spectra IPG with four linear ST leads of 50 or $70 \mathrm{~cm}$ (model no. M365SC2218500 and M365SC2218700), the FreeLink remote control system (model no. M365SC52500), and the standard wireless charging system (model no.M365SC641230); all programming was done using the Clinician Programmer (model no. M365SC7150400) and associated programming software, the BionicNavigator 01.2.

\section{Paraclinical Investigations}

\section{Diagnostic Imaging}

Eight patients had bedside ultrasound of the pacemaker site performed by a physician including a clinical examination after $3,7,14,21$, and 42 days.

Eight patients had a postoperative CT scan performed approximately 10 days and 8 weeks after surgery to check for lead migration/displacement.

All CT scans were performed without intravenous contrast as diagnostic scans (not low dose), from the umbilical region and downward to the proximal femur region. The average cumulative radiation dose per patient was $8 \mathrm{mSv}$ (range: 6-10.9). Coronal and sagittal, $2 \mathrm{~mm}$ slice thickness, reconstructions were made.

Optimal lead placement was defined as the location of the sciatic nerve electrode leads near the greater sciatic foramen. Distance from the acetabular roof to the SNEL, chiefly measured in sagittal reconstructions, was used to evaluate the precise migration/displacement.

Femoral nerve electrode lead (FNEL) near to the musculus iliopsoas and inguinal canal was decided as an optimal placement. Distance from the superior iliac spine anterior to the FNEL top on coronal reconstructions was used to evaluate the precise migration/ displacement. See Figure 1 for an example of well-placed leads. Arrows indicate the lead and IPG placement.

\section{Blood Samples}

Blood samples measuring C-reactive peptide (CRP) were drawn on the day of operation and daily until discharge from the hospital. Patients had a clinical follow-up between postoperative days 7 to 10, where CRP measures were obtained as well.

\section{Clinical Assessment}

Eligible patients were examined by specialist neurologists and evaluated by trained neurorehabilitation physiotherapists regarding compliance before participation.

\section{Study Procedure}

The Possover LION procedure involved laparoscopic exposure of both the femoral and sciatic nerves bilaterally. For a comprehensive description, we refer to the International School of Neuropelveology textbook 2015. 
Pneumoperitoneum was formed, an umbilical $12-\mathrm{mm}$ port was introduced for the camera, and further three 12-mm ports were placed in the lower abdomen.

Exposure of the femoral nerves was done by incising the fascia parallel to the lateral border of the psoas muscle (see Fig. 2). The femoral nerve was located by deepening this parallel dissection into the space between the psoas and iliac muscles.

Exposure of the lumbosacral truncus and sciatic nerves was achieved by pursuing the space between the medial border of the psoas muscle and the external iliac vessels, the lumbosacral space (see Fig. 3). The lumbosacral trunk and sciatic nerves were located in the bottom of the lumbosacral space.

After exposure of the femoral and sciatic nerves bilaterally, a tunneling device was introduced through the lower port holes on each side. This was introduced retroperitoneally down to the exposed femoral and sciatic nerves. The tunneling device was covered by an introducer sheath, and when the device was removed, leads were introduced and placed along the nerves (see Fig. 4).

The leads were then tunneled subcutaneously to the IPG site. Intraoperative impedance measurements and stimulation

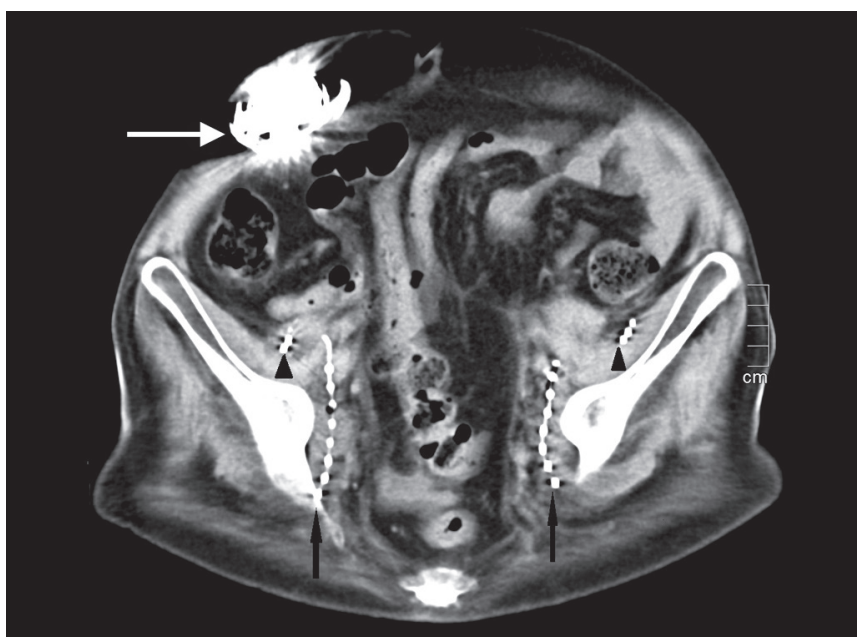

Fig. 1: CT scan showing the correct placement of IPG, femoral lead, and sciatic lead

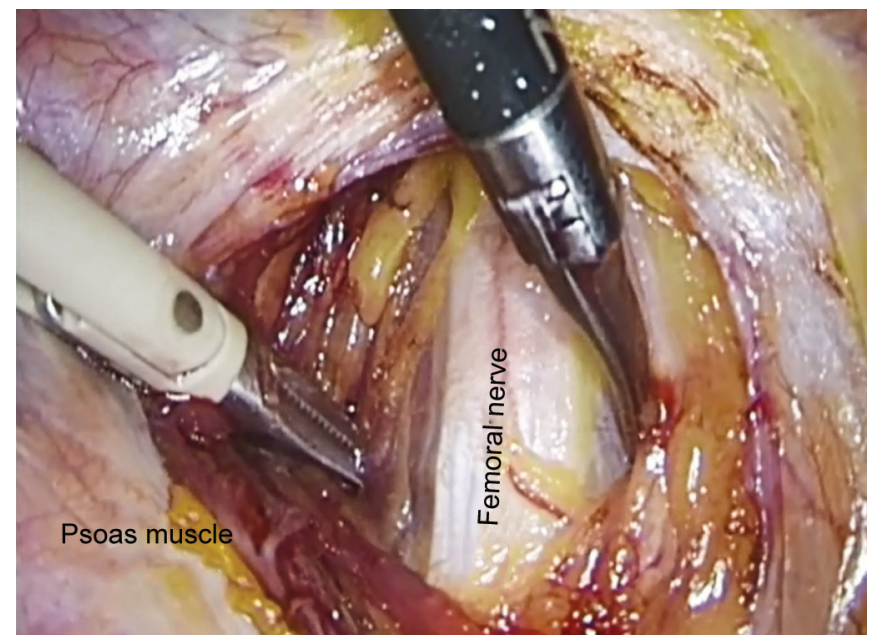

Fig. 2: Laparoscopic exposure of the femoral nerve tests were employed to ensure lead continuity and placement. Leads were then connected to the IPG, which was placed in a subcutaneous pocket on the abdominal wall and firmly fixed with non-resorbable sutures to prevent displacement. The skin was closed with subcutaneous sutures and staples.

\section{Stimulation Procedure}

After implantation, three different modes of stimulation were compiled into four subject-activated programs uploaded to the IPG (see Table 1); all program settings were based on Possover's original constructs. Program A was initiated after 2 weeks, programs $B$ and $C$ were initiated after 6 weeks, and program $D$ was only initiated when sufficient muscle strength had developed to support standing (approximately 20-26 weeks).

Patient demographics are reported in Table 2. Twenty eligible $\mathrm{SCl}$ persons ( 3 women and $17 \mathrm{men}$ ) who had sustained a traumatic $\mathrm{SCl}$, with an age of (mean \pm SD) $36.3 \pm 9.0$, had the procedure performed. The marital status was married/ common law in 10 and single in nine patients, respectively. The educational level was common school in four patients, high school in four patients, bachelor/profession in 10 patients,

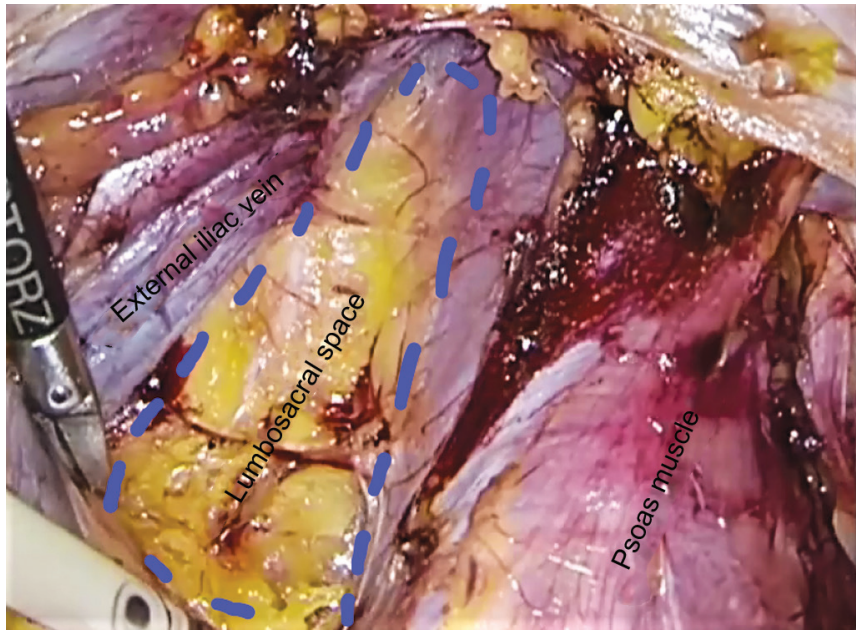

Fig. 3: Laparoscopic exposure of the lumbosacral space

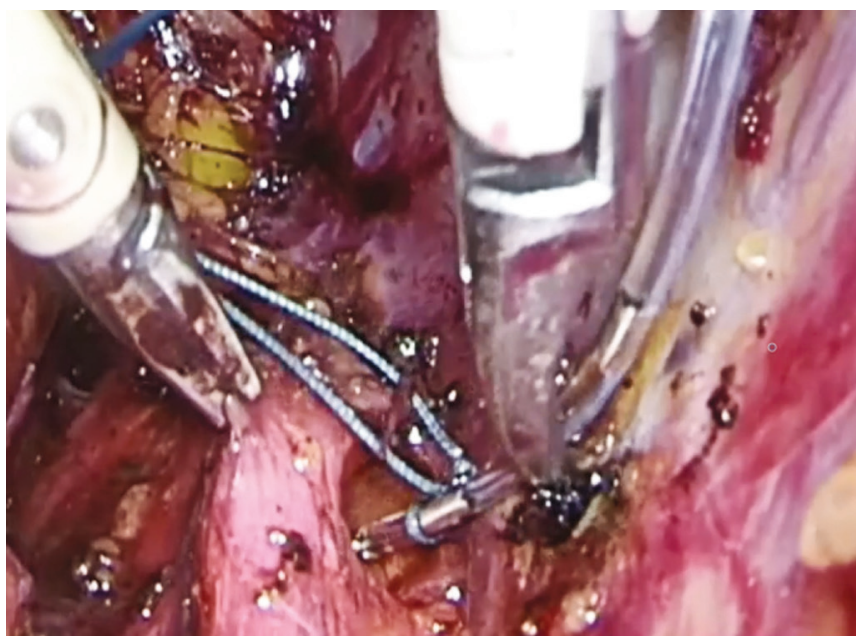

Fig. 4: Placement of lead under the sciatic nerve 
Table 1: IPG programs

Program A Continuous stimulation using all four leads with the lowest current intensity needed for subclinical skeletal muscle contraction.

- Frequency: $5-10 \mathrm{~Hz}$

- Pulse width: 50-150 $\mu \mathrm{s}$

- Current intensity: variable

Programs Stimulation for 20-30 minutes during training sessions $B$ and $C$ every other day with current intensities needed for minimal-maximal knee extension ( $B$, femoral leads) and gluteal contractions ( $C$, sciatic leads).

- Frequency: $30-60 \mathrm{~Hz}$

- Pulse width: 50-150 $\mu$ s

- Current intensity: variable

Program D Stimulation on all four leads for training of stance and gait.

- Frequency: $30-60 \mathrm{~Hz}$

- Pulse width: 50-150 us

- Current intensity: variable

and university degree in two patients. Nineteen patients had complete paraplegia ISCNSCI AIS A, while one patient was incomplete ISNCSCI AIS B. The spinal cord lesion was situated between Th3-Th6 in 10 patients and between Th7-Th12 in seven patients and between L1-4 in three patients.

\section{Bleeding}

During operation, one patient had major bleeding of $900 \mathrm{~mL}$, which was stopped by locally applied hemostats. No transfusion was required.

One patient presented with an intramuscular hematoma of both pectineus muscles 8 weeks post-surgery, confirmed by CT scan. This was caused by stretching of the muscles during physiotherapy and ongoing stimulation and resolved without further problems.

\section{Infections}

Pre- and postoperative blood samples (CRP) were obtained.

One patient presented with infection in close vicinity to the IPG 30 days post-surgery. Before this, the patient's CRP values were normalized on postoperative day 7 . The discharge was sent for culture and sensitivity, uncovering a bacterial infection with Staphylococcus aureus. The infection was managed with antibiotics (dicloxacillin) and negative pressure wound therapy; however, the infection did not resolve, and subsequently, the IPG and the two leads were surgically removed.

One patient suffered from a bladder infection that was treated with antibiotics.

\section{IPG-related Complications}

Displacement of the IPG was observed in one patient. The IPG tilted away from the fascia obstructing recharging the IPG. The patient was electively re-operated and had the IPG replaced. After this, no further complications followed. One patient developed localized necrosis of the skin covering the IPG site. The skin healed by locally applied negative pressure wound therapy.

\section{Diagnostic Imaging}

In one patient, bedside ultrasonography showed a fluid collection around the IPG on day 7. The patient had no other complaints nor clinically observable findings; the minor seroma had disappeared on day 14. The results from the CT scans are presented in Table 3. Two patients did not show up for the CT scan on week 8 (marked as "missing"). No patients had seroma formation along the leads or IPG.

One patient had a visible displacement of two leads to the femoral and sciatic nerves on day 10 , requiring a surgical intervention with repositioning off the leads. A control CT 8 weeks postoperatively showed that all leads were in place.

CT scans 8 weeks postoperatively revealed further displacement of the leads in three patients; clinically significant displacement requiring surgery was found in one patient. Replacement of the leads was not possible due to fibrosis in the lumbosacral space, and the leads and IPG were removed.

Right SNEL in patient 13 migrated $1.5 \mathrm{~cm}$ up on control CT but was still in contact to the sciatic nerve. Left FNEL migrated $4 \mathrm{~cm}$ up, and right FNEL migrated slightly medially in patient 13 on control CT. Right FNEL migrated $5 \mathrm{~cm}$ up in patient 16 on control CT.

\section{Discussion}

The Possover LION procedure is a promising new treatment for paraplegic patients. It shares features with epidural spinal cord stimulation (SCS), which has recently been reported to induce the recovery of some motor function. ${ }^{12}$ It is a technically challenging operation, but the presented series show that the procedure is safe and with a similar or even more favorable risk of complications than SCS, which ranges from 8 to $75 \% .{ }^{13,14}$ The Possover LION procedure may be performed in a day-surgery setting, although we elected to admit patients until post-op day 1 in order to avoid lead displacements.

The effect of both the Possover LION procedure and SCS on motion function in paraplegics is still controversial, and certainly more controlled studies are needed to determine the role of these procedures. Our group will soon publish functional outcomes from the randomized controlled study (substudy 2). A new randomized controlled study is planned for year 2021, in which we will investigate cardiovascular and musculoskeletal effects of the Possover LION procedure. Safety data from the present article will help to justify these new clinical studies.

A CT scan provides an accurate way of detecting lead displacement. Twenty-five percent of the patients undergoing CT scanning had a clinically significant lead dislocation, although of the total patient group, only $10 \%$ had clinically significant lead dislocation. The scans were in concordance with the clinical presentation, and patients similarly presented with a loss of muscle activation during stimulation from the dislocated leads, which indicated a need for re-operation. It was possible to access the lumbosacral space around post-op day 10, enabling safe repositioning of the displaced leads. In our experience, surgery in the lumbosacral space past the "surgical window" of approximately 12 days is not possible. This emphasizes the importance of a routine CT scan 10 days post-op. Lead displacement was encountered during the first few days after surgery, but as shown in Table 2, the displacement may occur much later. Infection rates were acceptable, being around $5 \%$ in this study, which is comparable to cardiac pacemaker implantations. ${ }^{15,16}$ CRP-level measurements postoperatively did not detect the one patient, who afterward developed an infection. The CRP levels were normalized before the patient reported discharge from the IPG site. The infection was localized and posed no threat to the patient. The removal of 
Table 2: Patient overview

\begin{tabular}{|c|c|c|c|c|c|c|c|c|c|c|c|}
\hline 00 & Age & Gender & $\begin{array}{l}\text { ISNCSCI } \\
\text { grades* }\end{array}$ & $\begin{array}{l}\text { Neurologic } \\
\text { level }\end{array}$ & $\begin{array}{l}\text { Age of injury } \\
\text { (year) }\end{array}$ & $\begin{array}{l}\text { Bleeding } \\
(\mathrm{mL})\end{array}$ & $\begin{array}{l}\text { Surgery time } \\
\text { (minutes) }\end{array}$ & System & ULS** & $C T^{* * * *}$ & Complications \\
\hline 1 & 45.1 & Male & $A$ & Th6 & 22.8 & 0 & 172 & $\begin{array}{l}\text { Boston } \\
\text { Spectra IPG }\end{array}$ & + & & None \\
\hline 2 & 26.3 & Female & A & Th7 & 2.4 & 0 & 176 & $\begin{array}{l}\text { Boston } \\
\text { Spectra IPG }\end{array}$ & + & & None \\
\hline 3 & 28.9 & Male & A & Th10 & 2.7 & 0 & 161 & $\begin{array}{l}\text { Boston } \\
\text { Spectra IPG }\end{array}$ & + & & None \\
\hline 4 & 45.4 & Male & A & Th12 & 16.2 & 0 & 191 & $\begin{array}{l}\text { Boston } \\
\text { Spectra IPG }\end{array}$ & + & & IPG dislocation \\
\hline 5 & 47.4 & Male & A & Th6 & 26.1 & 900 & 343 & $\begin{array}{l}\text { Boston } \\
\text { Spectra IPG }\end{array}$ & + & & Bleeding \\
\hline 6 & 33.7 & Male & A & Th3 & 16.9 & 0 & 125 & $\begin{array}{l}\text { Boston } \\
\text { Spectra IPG }\end{array}$ & + & & None \\
\hline 7 & 22.6 & Male & A & Th5 & 2.4 & 0 & 185 & $\begin{array}{l}\text { Boston } \\
\text { Spectra IPG }\end{array}$ & + & & None \\
\hline 8 & 28.1 & Male & A & Th5 & 9.3 & 0 & 224 & $\begin{array}{l}\text { Boston } \\
\text { Spectra IPG }\end{array}$ & + & & None \\
\hline 9 & 47.0 & Male & A & Th6 & 16.8 & 0 & 192 & $\begin{array}{l}\text { Boston } \\
\text { Spectra IPG }\end{array}$ & & + & None \\
\hline 10 & 49.8 & Male & A & L1 & 24.4 & 0 & 309 & $\begin{array}{l}\text { Boston } \\
\text { Spectra IPG }\end{array}$ & & + & $\begin{array}{l}\text { Mild/moderate pain in } \\
3-4 \text { days self-limiting }\end{array}$ \\
\hline 11 & 35.5 & Male & A & Th8 & 9.1 & 0 & 137 & $\begin{array}{l}\text { Boston } \\
\text { Spectra IPG }\end{array}$ & & + & Lead dislocation \\
\hline 12 & 34.4 & Male & A & Th5 & 17.6 & 0 & 213 & $\begin{array}{l}\text { Boston } \\
\text { Spectra IPG }\end{array}$ & & + & $\begin{array}{l}\text { Urine blurred at } \\
\text { dismission, need for } \\
\text { antibiotics } 6 d\end{array}$ \\
\hline 13 & 31.3 & Male & A & Th11 & 2.9 & 0 & 191 & $\begin{array}{l}\text { Boston } \\
\text { Spectra IPG }\end{array}$ & & + & None \\
\hline 14 & 46.0 & Male & A & Th4 & 26.5 & 0 & 169 & $\begin{array}{l}\text { Boston } \\
\text { Spectra IPG }\end{array}$ & & + & $\begin{array}{l}\text { Necrosis of the skin } \\
\text { above IPG poche, healed } \\
\text { by vacuum therapy }\end{array}$ \\
\hline 15 & 43.2 & Female & A & Th8 & 24.7 & 0 & 194 & $\begin{array}{l}\text { Boston } \\
\text { Spectra IPG }\end{array}$ & & + & Lead dislocation \\
\hline 16 & 30.4 & Male & A & Th7 & 8.4 & 0 & 139 & $\begin{array}{l}\text { Boston } \\
\text { Spectra IPG }\end{array}$ & & + & None \\
\hline 17 & 44.8 & Male & A & Th4 & 3.7 & 0 & 147 & $\begin{array}{l}\text { St Jude/ } \\
\text { Abbott EON } \\
\text { Mini IPG }\end{array}$ & & & None \\
\hline 18 & 26.8 & Female & A & Th5 & 1.3 & 0 & 182 & $\begin{array}{l}\text { St Jude/ } \\
\text { Abbott EON } \\
\text { Mini IPG }\end{array}$ & & & None \\
\hline 19 & 28.5 & Male & A & L3 & 10.1 & 0 & 125 & $\begin{array}{l}\text { St Jude/ } \\
\text { Abbott EON } \\
\text { Mini IPG }\end{array}$ & & & $\begin{array}{l}\text { Neuropraxia, left ischiadic } \\
\text { nerve, normalized after } \\
\text { several months. Hardware } \\
\text { malfunction. }\end{array}$ \\
\hline 20 & 21.6 & Male & B & Th7 & 1.6 & 0 & 132 & $\begin{array}{l}\text { St Jude/ } \\
\text { Abbott EON } \\
\text { Mini IPG }\end{array}$ & & & $\begin{array}{l}\text { Infection causing } \\
\text { explantation of } \\
\text { electrodes and IPG }\end{array}$ \\
\hline
\end{tabular}

*ISNCSCI, International Standards for Neurological Classification of Spinal Cord Injury;

**Ultrasound examination of IPG-area;

***Diagnostic CT abdomen, from the umbilical region with coronal and sagittal reconstructions made

the leads and the IPG was done externally without laparoscopy. Within colorectal surgery, postoperative CRP measurements may predict anastomotic leaks, ${ }^{17}$ but with the Possover LION procedure, clinical wound examination may be necessary to detect postoperative infection. This corresponds with local infections seen after the implantation of cardiac pacemakers, which are often diagnosed only by swelling, redness, and tenderness of the skin. ${ }^{18}$ 


\begin{tabular}{|c|c|c|}
\hline $\begin{array}{l}\text { Patient } \\
\text { No. }\end{array}$ & $\begin{array}{l}\text { CT scan } 10 \text { days } \\
\text { after operation }\end{array}$ & $\begin{array}{l}\text { CT scan } 8 \text { weeks } \\
\text { after operation }\end{array}$ \\
\hline 9 & No dislocation & No dislocations \\
\hline 10 & No dislocation & Missing \\
\hline 11 & $\begin{array}{l}\text { Left femoral lead } \\
\text { dislocated }\end{array}$ & $\begin{array}{l}\text { Left }+ \text { Right femoral leads dislocated } \\
\text { from nerves }\end{array}$ \\
\hline 12 & No dislocation & Missing \\
\hline 13 & No dislocation & $\begin{array}{l}\text { Slight dislocation of three electrodes, } \\
\text { still in contact with nerves }\end{array}$ \\
\hline 14 & No dislocation & No dislocation \\
\hline 15 & $\begin{array}{l}\text { Dislocation of } \\
\text { right femoral and } \\
\text { sciatic electrodes }\end{array}$ & $\begin{array}{l}\text { After surgical correction, no } \\
\text { electrodes dislocated }\end{array}$ \\
\hline 16 & No dislocation & $\begin{array}{l}\text { Slight dislocation of the right femoral } \\
\text { lead, still in contact with nerve }\end{array}$ \\
\hline
\end{tabular}

\section{Conclusion}

The Possover LION procedure may be performed safely in patients with thoracolumbar traumatic SCl. The election of suitable patients for the operation should include a specialist team of skilled neurologists, neurorehabilitation physiotherapists, and highly experienced pelvic surgeons. We recommend that the Possover LION procedure is performed only at expert centers with experienced pelvic surgeons and a team of neurologists and physiotherapists dedicated to patient training and follow-up. The International Society of Neuropelveology (ISON) offers theoretical and practical training in the LION procedure, and we highly recommend certification by this Society before undertaking the Possover LION procedure.

\section{Acknowledgments}

The study was supported by, and received financial support from, the Viborg Regional Hospital and the Central Denmark Region Health Research Fund.

\section{ORCID}

Uffe S Løve iㅏ https://orcid.org/0000-0002-2409-0499

\section{References}

1. Lundberg AS, Andersen MK, Kasch H, et al. [Patients with spinal cord injuries experience many sequelae]. Ugeskr Laeger 2015;177(43):V06150476.

2. Taweel WA, Seyam R. Neurogenic bladder in spinal cord injury patients. Res Rep Urol 2015;7:85-99. DOI: 10.2147/RRU.S29644.

3. van Middendorp JJ, Hosman AJ, Pouw MH, et al. ASIA impairment scale conversion in traumatic $\mathrm{SCl}$ : is it related with the ability to walk? A descriptive comparison with functional ambulation outcome measures in 273 patients. Spinal Cord 2009;47(7):555-560. DOI: 10.1038/sc.2008.162.

4. Fawcett JW, Curt A, Steeves JD, et al. Guidelines for the conduct of clinical trials for spinal cord injury as developed by the ICCP panel: spontaneous recovery after spinal cord injury and statistical power needed for therapeutic clinical trials. Spinal Cord. 2007;45(3):190-205. DOI: 10.1038/sj.sc.3102007.

5. Elmgreen SB, Krogh S, Løve US, et al. [Neuromodulation in spinal cord injury rehabilitation]. Ugeskr Laeger 2019;181(26).

6. Possover M. A new technique of laparoscopic implantation of stimulation electrode to the pudendal nerve for treatment of refractory fecal incontinence and/or overactive bladder with urinary incontinence. J Minim Invasive Gynecol 2014;21(5):729. DOI: 10.1016/j. jmig.2014.02.003.

7. Possover M. A novel implantation technique for pudendal nerve stimulation for treatment of overactive bladder and urgency incontinence. J Minim Invasive Gynecol 2014;21(5):888-892. DOI: 10.1016/j.jmig.2014.03.026.

8. Possover M. The LION procedure to the pelvic nerves for treatment of urinary and faecal disorders. Surg Technol Int 2014;24:225-230.

9. Possover M. Recovery of sensory and supraspinal control of leg movement in people with chronic paraplegia: a case series. Arch Phys Med Rehabil 2014;95(4):610-614. DOI: 10.1016/j.apmr.2013.10.030.

10. Possover M, Schurch B, Henle KP. New strategies of pelvic nerves stimulation for recovery of pelvic visceral functions and locomotion in paraplegics. Neurourol Urodyn 2010;29(8):1433-1438. DOI: 10.1002/ nau.20897.

11. Possover M. The LION procedure to the pelvic nerves for recovery of locomotion in 18 spinal cord injured peoples - a case series. Surg Technol Int 2016;29:19-25.

12. Angeli CA, Boakye M, Morton RA, et al. Recovery of over-ground walking after chronic motor complete spinal cord injury. N Engl J Med 2018;379(13):1244-1250. DOI: 10.1056/NEJMoa1803588.

13. Bendersky D, Yampolsky C. Is spinal cord stimulation safe? A review of its complications. World Neurosurg 2014;82(6):1359-1368. DOI: 10.1016/j.wneu.2013.06.012.

14. Kleiber JC, Marlier B, Bannwarth M, et al. Is spinal cord stimulation safe? A review of 13 years of implantations and complications. Rev Neurol (Paris) 2016;172(11):689-695. DOI: 10.1016/j.neurol.2016.09.003.

15. Döring $M$, Richter $S$, Hindricks $G$. The diagnosis and treatment of pacemaker-associated infection. Dtsch Arztebl Int 2018;115(26): 445-452. DOI: 10.3238/arztebl.2018.0445.

16. Eldabe S, Buchser E, Duarte RV. Complications of spinal cord stimulation and peripheral nerve stimulation techniques: a review of the literature. Pain Med 2016;17(2):325-336. DOI: 10.1093/pm/pnv025.

17. Singh PP, Zeng IS, Srinivasa $S$, et al. Systematic review and metaanalysis of use of serum C-reactive protein levels to predict anastomotic leak after colorectal surgery. Br J Surg 2014;101(4): 339-346. DOI: 10.1002/bjs.9354.

18. Blomström-Lundqvist C, Traykov V, Erba PA, et al. European Heart Rhythm Association (EHRA) international consensus document on how to prevent, diagnose, and treat cardiac implantable electronic device infections-endorsed by the Heart Rhythm Society (HRS), the Asia Pacific Heart Rhythm Society (APHRS), the Latin American Heart Rhythm Society (LAHRS), International Society for Cardiovascular Infectious Diseases (ISCVID) and the European Society of Clinical Microbiology and Infectious Diseases (ESCMID) in collaboration with the European Association for Cardio-Thoracic Surgery (EACTS). Europace 2020;22(4):515-549. DOI: 10.1093/europace/euz246. 